\title{
sciendo
}

CIVIL AND ENVIRONMENTAL ENGINEERING REPORTS

E-ISSN 2450-8594

CEER 2021; 31 (1): 0001-0028

DOI: $10.2478 /$ ceer-2021-0001

Original Research Article

\section{EXPERIMENTAL STUDY \\ ON THE DURABILITY CHARACTERISTICS \\ OF SEVERAL VEGETABLE FIBER REINFORCED CONCRETES EXPOSED TO SODIUM SULFATE}

Sami ZIANE ${ }^{1}$, Mohammed-Rissel KHELIFA², Samy MEZHOUD ${ }^{3 *}$, Ahmed BEROUAL ${ }^{1}$, Saber MEDAOUD ${ }^{4}$

${ }^{1}$ Laboratory of Soil Mechanics and structures (LMSS), Dept. of Civil Engineering, Faculty of Science and Technology, University of Mentouri Brothers Constantine 1, Constantine, Algeria

${ }^{2}$ Department of Civil Engineering, Faculty of Technology, University of Batna 2, Batna, Algeria

${ }^{3}$ Departments of Geography and Land Sciences, University of Mentouri Brothers Constantine1, Constantine, Algeria

${ }^{4}$ Department of Civil Engineering, Ferhat Abbas Sétif University 1, Sétif, Algeria

\section{Abstract}

Recently, numerous plant fibers have been investigated as a means to reinforce concrete and replace synthetic fibers, thereby producing more eco-friendly concretes. The primary concern for these studies is the durability of the fibers in the external environment. For this purpose, the current paper presents a comparison study on the physical-mechanical behavior and durability against external sulfatic attack on Alfa and Hemp fiber-reinforced concrete. To assess the effects of sulfatic attack, different types of concrete underwent two aging protocols: 1) a complete immersion in $12.5 \%$ Sodium Sulfate $\left(\mathrm{Na}_{2} \mathrm{SO}_{4}\right)$ solution and, 2) an accelerated aging protocol which consisted of immersion/drying in the same sulfate solution at a temperature of $60^{\circ} \mathrm{C}$. The results show that the optimal amount of

\footnotetext{
* Corresponding author: Department of Geography and Land Sciences, University of Mentouri Brothers Constantine1, Constantine, Algeria e-mail: mezhoud.sami@umc.edu.dz
} 
plant fiber is variable, depending on several parameters such as the chemical composition, mechanical characteristics, and morphology of the fiber. In addition, the results show that the use of Alfa and hemp fibers could facilitate the production of green and durable structural concretes.

Keywords: reinforced concrete, remp fibers, alfa fibers, polypropylene fibers, durability, sulfatic attacks

\section{INTRODUCTION}

Concrete is the most widely used construction material today. It is an economic material with good compressive strength [1], however, concrete structures are regularly subjected to aggressive environmental conditions from a variety of naturally occurring and industrial chemicals. One of the most prevalent and common forms of chemical attack is the action of sulfates on concrete components [2].

External Sulfatic Attack (ESA) is a reaction between Sulfate ions, which come from an external environment (present in groundwater, seawater, soils, and wastewaters), and hydration products of cement such as $\mathrm{CH}(\mathrm{OH})_{2}$ and C.S.H. This reaction leads to the formation of gypsum, ettringite, and/or thaumasite and may cause a lowering of the concrete's strength, expansion, and surface scaling $[3,4]$.

In addition, cracks are considered as a major problem in the cementitious matrix $[5,6]$, and which can increase the severity of these external attacks. To reduce these problems, reinforcing fibers can be integrated into the concrete, leading to increased tensile strength, ductility, toughness, and thus, durability [7]. Several types of fibers have been used in Fiber Reinforced Concrete (FRC) compositions such as synthetic (metallic, organic such as polypropylene) or natural (mineral, vegetal, and animal). According to their nature, they variously contribute to the properties of the composite. Nowadays, biological composite materials have been the focus of academic and industrial investigations [8]. The use of plant fibers in composites as a reinforcing material has attracted the attention of researchers in the field of civil engineering in recent years, as substitutes to synthetic fibers such as polypropylene. This interest is growing for several reasons: (1) economic: create or develop economical activities in remote areas; (2) social: maintain agriculture in such areas (3) environmental: replace industrial components in concrete and valorize waste of agriculture origin $[9,10]$.

In general, the composition and properties of plant fibers vary depending on the origin and type of fibers, the species of plant, and the environment in which the original plant is growing [11]. Most of the vegetal fibers such as flax [12], dis [13], palmer [14], doum [15], and bamboo [16], are examples of sustainable materials that are being widely explored by numerous researchers. Despite all this 
interest, little research has focused on the durability of concretes based on these natural fibers. Thus, in this work, our attention is oriented towards the study of the durability of concrete reinforced with alfa fibers and hemp fibers, because these two fibers have not been well considered in concrete reinforcement.

"Alfa" is the Arabic name of the stipa tenacissima plant, a fast-growing perennial plant that thrives in the dry regions of north Africa (mainly in the Maghreb) and the southeast of Spain. The Alfa is a grey-green needle grass made of long stems with seed heads and leaves, which acts as a barrier against desertification in the Maghreb area and, therefore, plays an important role in the protection of ecosystems $[17,18]$. On the other hand, hemp is one of the oldest-known plants and has been used in a variety of applications, making it one of the most recognizable plants in the world. It belongs to the cannabinaceae family, characterized by a height of up to 4 meters, and cultivated particularly in countries with a temperate climate such as France, Spain, and Canada [19,20].

In this paper, we pay particular attention to evaluating the physical and mechanical performance of concrete reinforced with Alfa fibers (AC) and Hemp fibers (HC) as well as their durability against external sulfatic attacks. The results are compared to an ordinary concrete (OC) and a concrete reinforced with polypropylene fibers (PC), to evaluate the production potential of greener structural concretes. Different amounts $(0.25 \%$ to $1.5 \%)$ of Alfa and Hemp fibers were added into the concrete mixture in order to determine the optimal amount of fibers to obtain both a durable and natural reinforced concrete. Compression and tensile strength tests were performed together with young's modulus variations and physical tests. Additionally, the durability of these concretes against sulfatic attack is studied. For this purpose, two aging protocols were used: 1) a complete immersion in $\mathrm{Na}_{2} \mathrm{SO}_{4}$ solution with a concentration of $12.5 \%$ by weight [21], and 2) the use of an accelerated aging protocol; an immersion/drying at $60^{\circ} \mathrm{C}$ in the same solution with the same concentration [22].

\section{MATERIALS}

The Alfa fibers used in this study were collected from the Djelfa area in Algeria. They had an average diameter of $10.2 \mu \mathrm{m}$ and $1082 \mu \mathrm{m}$ and were cut to an approximate length of $20 \mathrm{~mm}$ (Figure. 1a), then impregnated with water for 2 hours in order to limit the absorption of water during the trial mix. Table 1 shows the physical-chemical characteristics of the Alfa fibers [23-25].

The hemp plant (Cannabis sativa L) used in this research is categorized as a bast fiber crop, obtained from the outer part of the stem by a mechanical threshing process. The process of hemp fiber extraction consists of several steps: harvesting, retting in the field, and exploitation of the hemp straw. The long hemp fibers were then cut to the desired lengths. In this study, the length of hemp fibers was $2 \mathrm{~cm}$ 
and the fibers come from Canada (Figure.1b). Table 2 shows the physicalchemical characteristics of the hemp fibers $[19,26]$.

The polypropylene fibers came from the TUF-STRAND MAXTEN brand of fibers (Figure. 1c). They are manufactured according to ASTM C 1116, Standard Specification for Fiber Reinforced Concrete and Shotcrete. They have a length of about $20 \mathrm{~mm}$. Table 3 gives their characteristics.

The cement used for all mixtures was a Portland Composite Cement (CEM II/A 42.5 ) with a density of $3.06 \mathrm{~g} / \mathrm{cm}^{3}$ and Blaine fineness of $3891 \mathrm{~g} / \mathrm{cm}^{2}$, conforming to European standard EN 197-1 [27]. The chemical composition of the cement is given in Table 4.

The sand is a calcareous $0 / 3 \mathrm{~mm}$ variety, with a specific gravity of $1440 \mathrm{~kg} / \mathrm{m}^{3}$, and a water absorption coefficient of $0.78 \%$ (in mass). The coarse aggregates are calcareous $(3 / 8 \mathrm{~mm}$ and $8 / 16 \mathrm{~mm})$, with a specific gravity of $1350 \mathrm{~kg} / \mathrm{m}^{3}$, and a water absorption coefficient of $0.72 \%$ (in mass). The size distribution graphs of all aggregates are given in Figure 2.

For all mixes, one type of chemical admixture (SUPERIOR RM 34) was used to provide better workability in the fresh state. This superplasticizer is based on modified silicate polycarbons, is compatible with all types of cement, is an Ether solution with a specific gravity of 1.1 at $25^{\circ} \mathrm{C}$, and complies with EN934-2 [28].

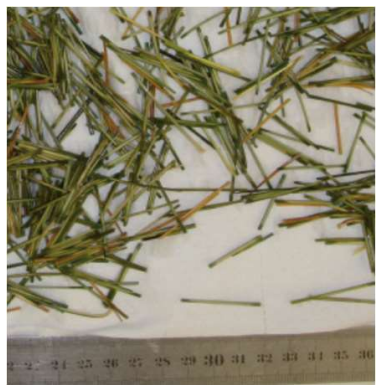

(a) Alfa fibers

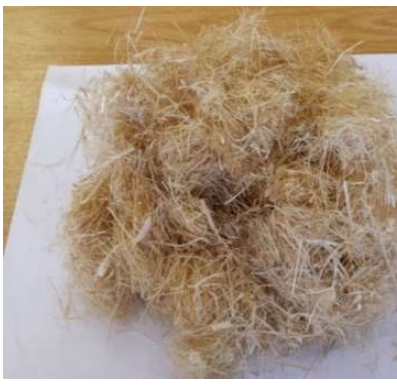

(b) Hemp fibers

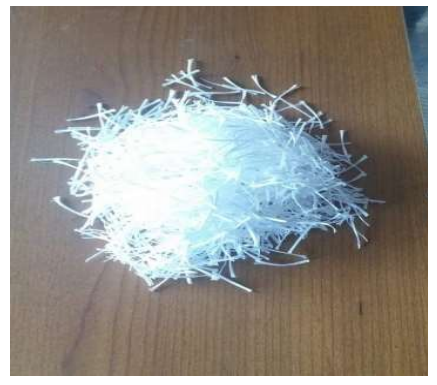

(c) Polypropylene fibers

Fig. 1. The fibers used for concrete reinforcement 
EXPERIMENTAL STUDY ON THE DURABILITY CHARACTERISTICS OF SEVERAL

Table 1. Physical, chemical, and mechanical characteristics of Alfa fibers

\begin{tabular}{lr}
\hline Chemical composition $(\%)$ & $\begin{array}{l}\text { Cellulose } 43-45 \\
\text { Hemicellulose 24 } \\
\text { Lignins 24 } \\
\text { pectin 5 }\end{array}$ \\
\hline Tensile strength $(\mathrm{MPa})$ & 165 \\
Young's modulus $(\mathrm{GPa})$ & $19.3 \pm .91$ \\
The density $\left(\mathrm{Kg} / \mathrm{m}^{3}\right)$ & $454-890$ \\
The porosity $(\%)$ & 53 \\
Diameter $(\mu \mathrm{m})$ & $10.2-1082$
\end{tabular}

Table 2. Physical, chemical, and mechanical characteristics of Hemp fibers

\begin{tabular}{lr}
\hline Chemical composition $(\%)$ & $\begin{array}{l}\text { Cellulose 56.1 } \\
\text { Hemicellulose :10.9 } \\
\end{array}$ \\
$\begin{array}{l}\text { Lignins 6 } \\
\text { pectin 20.1 }\end{array}$ & $59-857$ \\
\hline Tensile strength $(\mathrm{MPa})$ & $38-58$ \\
Young's modulus $(\mathrm{GPa})$ & 1400 \\
The density $\left(\mathrm{Kg} / \mathrm{m}^{3}\right)$ & $180-105$ \\
The porosity $(\%)$ & $16-50$ \\
Diameter $(\mu \mathrm{m})$ & \\
\hline
\end{tabular}

Table 3. Characteristics of Polypropylene fibers

\begin{tabular}{lr}
\hline Parameters & Value \\
\hline Mass density & $910 \mathrm{~kg} / \mathrm{m}^{3}$ \\
The amount of polypropylene & $1.8-3 \% \mathrm{~kg} / \mathrm{M}^{3}$ \\
Young's modulus & $3500-3900 \mathrm{MPa}$ \\
Tensile strength & $600-650 \mathrm{MPa}$ \\
Melting point & $165^{\circ} \mathrm{C}$ \\
Water absorption & negligible \\
\hline
\end{tabular}


Table 4. Chemical composition of the cement

\begin{tabular}{lr}
\hline $\mathrm{Cement}$ & Content (\%) \\
\hline $\mathrm{SiO}_{2}$ & 23.25 \\
$\mathrm{Al}_{2} \mathrm{O}_{3}$ & 5.69 \\
$\mathrm{Fe}_{2} \mathrm{O}_{3}$ & 3.36 \\
$\mathrm{CaO}$ & 60.25 \\
$\mathrm{MgO}$ & .74 \\
$\mathrm{SO}$ & .94 \\
$\mathrm{~K}_{2} \mathrm{O}$ & .45 \\
$\mathrm{Na}_{2} \mathrm{O}$ & .27 \\
Equivalent $\mathrm{Na}_{2} \mathrm{O}$ & .98 \\
\hline
\end{tabular}

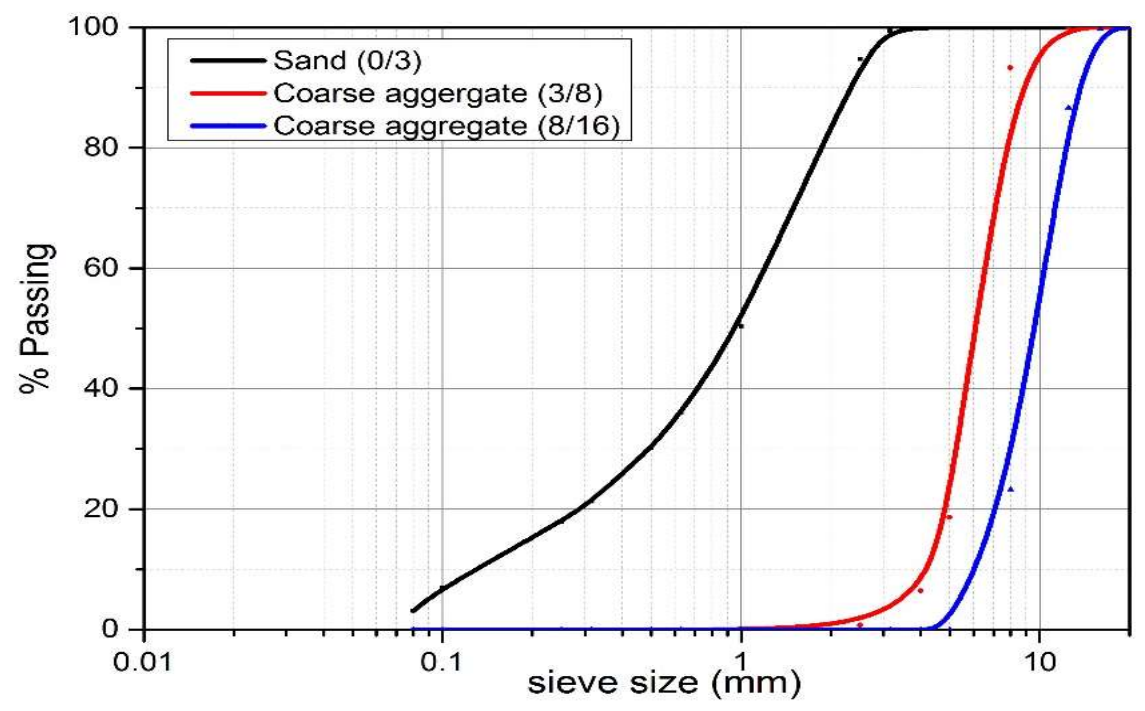

Fig. 2. Particle size distribution of sand and coarse aggregate

\section{EXPERIMENTAL PROGRAM AND TESTS CARRIED OUT}

\subsection{Mix design}

In this study, four different concrete mixes were prepared: 1) Two concretes incorporating Alfa (AC-1; AC-1.5; respectively $1 \%$ and 1,5\% of Alfa fibers by volume); 2) Three concretes incorporating hemp (HC-0.25; AC-0.5 and $\mathrm{HC}-1$ respectively $0.25,0.5$ and $1 \%$ of hemp fibers by volume); 3 ) Concrete incorporating $0.2 \%$ volume of polypropylene fibers (PC) and; 4) Ordinary 
concrete $(\mathrm{OC})$ as a reference material. The composition of all concrete mixes is given in Table 5.

The fibers, whatever their natures, were incorporated into the concrete mixture as an additional component and not as a substitution of another component, e.g. aggregates. The different quantities of Alfa and hemp fibers were tested in order to determine the best amount for the formulation of structural concrete. The amount of $0.25 \%$ to $1.5 \%$ is similar to that recommended by the manufacturer for the use of polypropylene fibers, which allows a direct comparison of the mechanical properties between the different composites. In addition, they were mixed with aggregates and cement before adding the water to guarantee uniform dispersion, which deals with the reinforcement capacity.

Table 5. Concrete mix design

\begin{tabular}{|c|c|c|c|c|c|c|c|}
\hline \multirow{2}{*}{ Mix proportion for $1 \mathrm{~m}^{3}$} & \multicolumn{7}{|c|}{ Mix code } \\
\hline & $\mathbf{O C}$ & PC & AC-1 & $\mathrm{AC}-1.5$ & HC-.25 & HC-.5 & HC-1 \\
\hline Cement $\left(\mathrm{kg} / \mathrm{m}^{3}\right)$ & 350 & 350 & 350 & 350 & 350 & 350 & 350 \\
\hline Sand $\left(\mathrm{kg} / \mathrm{m}^{3}\right)$ & 727 & 727 & 727 & 727 & 727 & 727 & 727 \\
\hline Coarse $3-8\left(\mathrm{~kg} / \mathrm{m}^{3}\right)$ & 109 & 109 & 109 & 109 & 109 & 109 & 109 \\
\hline Coarse $8-16\left(\mathrm{~kg} / \mathrm{m}^{3}\right)$ & 897 & 897 & 897 & 897 & 897 & 897 & 897 \\
\hline Superplasticizer volume (\%) & 0,6 & 0,6 & 0.6 & 1 & 0,6 & 2 & 2 \\
\hline Water $\left(\mathrm{kg} / \mathrm{m}^{3}\right)$ & 140 & 140 & 140 & 140 & 140 & 140 & 140 \\
\hline Hemp fibers $(\%)$ in $1 \mathrm{~m}^{3}$ of concrete & - & - & - & - & 0.25 & 0.50 & 1.00 \\
\hline Alfa fibers $(\%)$ in $1 \mathrm{~m}^{3}$ of concrete & & - & 1 & - & - & - & - \\
\hline $\begin{array}{l}\text { Polypropylene fibers }(\%) \text { in } 1 \mathrm{~m}^{3} \text { of } \\
\text { concrete }\end{array}$ & - & 0.25 & - & 1.5 & - & - & - \\
\hline
\end{tabular}

\subsection{Experimental program}

After dry and humid mixing of the different components in a mixer with a vertical axis and planetary motion, fresh and hardened tests were carried out. The slump test was used to quantify the workability of concrete according to the standard NF EN 12350-2 [29]. Next, for each concrete mixture, cylindrical specimens $(10 \times 20 \mathrm{~cm})$ and prismatic specimens $(7 \times 7 \times 28 \mathrm{~cm})$ were prepared for compressive and tensile strengths tests. After casting, all the specimens were moist cured at $20 \pm 2{ }^{\circ} \mathrm{C}$ and $50 \pm 5 \%$ of relative humidity until the required age of testing $(7,28,90$, and 120 days). 
In the hardened state, the characterization of mixes was carried out by the following methods and according to the standards. For each test and age, the measurements were carried out on three specimens for all mixes and the average values are reported. The tensile and compressive strengths were determined according to the NF P15-471 [30], and Dynamic Young's modulus was measured according to NF P 18-414 [31]. The open porosity and capillary absorption of the concretes were determined using a procedure based on that recommended by AFPC-AFREM (1997) [32].

\subsection{Sulfatic attacks protocols}

\subsubsection{The complete immersion protocol}

This is the protocol most frequently used in the literature to simulate a sulfatic attack on concrete in saline soils such as gypsum soils [33]. The cubic specimens $(7 \times 7 \times 7 \mathrm{~cm})$ of concrete are completely immersed in a $12.5 \%$ by weight Sodium Sulfate $(\mathrm{Na} 2 \mathrm{SO} 4)$ solution at $20^{\circ} \mathrm{C}$, renewed every 30 days.

To monitor the behavior of the samples subjected to Sulfatic attack over time, mass loss monitoring was selected at different time intervals over a period of 270 days. The compressive strength of different concretes was calculated after 28 days of normal cure, and then after 45 days, 90 days, 180 days, and 270 days of total immersion.

\subsubsection{Immersion/drying cycles at $60^{\circ} \mathrm{C}$}

This is a protocol for accelerating the aging of concrete based on 24-hour immersion cycles $[21,34]$. It is defined as follows:

- Immersion (4 hours) of the specimens in a $12.5 \%$ Sodium Sulfate $\left(\mathrm{Na}_{2} \mathrm{SO}_{4}\right)$ solution by mass.

- Drying ( 20 hours) in an oven at $60^{\circ}$. This temperature level was selected to avoid the superposition with the internal Sulfatic attack from the delayed formation of ettringite [35-37].

Daily, the mass of each sample is measured after the drying phase. The samples are tested with a compression test after 28 days of normal cure and at $5,15,30$, and 60 cycles of immersion, to follow the evolution of their mechanical performance. 


\section{RESULTS AND DISCUSSION}

\subsection{Concrete workability}

The results of the slump test are presented in Figure 3. Two groups of concrete can be distinguished: 1) very plastic concretes of class S3 $(110-140 \mathrm{~mm})$ for OC, PC, AC-1, and HC-0.25, 2) plastic concrete of class S2 (90 mm; AC-1.5) and, 3) stiff concretes of class $\mathrm{S} 1(50 \mathrm{~mm})$ for $\mathrm{HC}-0.5$ and $\mathrm{HC}-1$.

It can be seen that the incorporation of vegetables (Alfa or Hemp) fibers leads to a decrease in concrete slump, reflecting a reduction of workability. This can be explained by the high porosity of vegetable fibers [10], which would cause a further increase in the water absorption amount proportionally with the amount of hemp or Alfa fibers. This result is in line with previous studies [6, 8].

It should be noted that $\mathrm{HC}-1$ and $\mathrm{AC}-1$ concrete show a remarkable difference from each other; AC-1 is a very plastic concrete while $\mathrm{HC}-1$ is a firm concrete. This result was obtained despite the increase in superplasticizer dosage from $0.6 \%$ to $2 \%$ by weight of cement in the case of $\mathrm{HC}-1$. This was due to the high amount and flexibility of hemp fiber compared to Alfa fiber, which can lead to the formation of "pellets" during the mixing process and makes the mixture stiff. For this reason, it is recommended to reduce the amount of hemp fibers to $0.25 \%$ of volume which gives an appropriate structural concrete slump [38]. It should be further noted that the superplasticizer was added to the mixes to maintain an appropriate level of workability (S2 - S3) and to obtain a structural concrete that is easy to place.

In the case of the PC concretes, there is a slight reduction in slump caused by the amount of water remaining on the surface of the polypropylene fibers; although these fibers do not absorb water, a small amount is retained on their surface. 


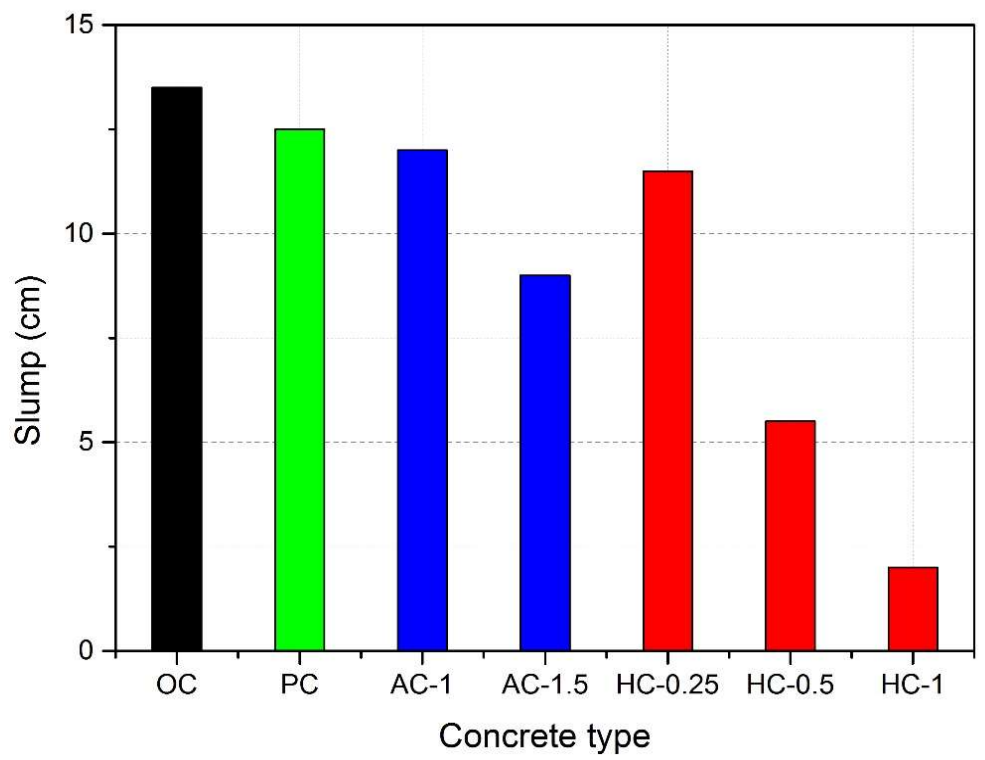

Fig. 3. The results of the slump test

\subsection{Porosity}

The variation of porosity as a function of fiber content is shown in Figure 4. The ordinary concrete (OC) is still the less porous concrete, while the $\mathrm{HC}-0.5$ and AC1.5 concrete are the most porous.

The total porosity increases with the increase of the amount of natural fiber. This circumstance is related to the initial porosity of natural fibers, the porosity of the cementitious matrix, and the interfacial transition zone (ITZ) around the fibers. The ITZ would be formed during the mixing due to the high water absorption coefficient of the natural fibers. This phase will induce a movement of water from the paste in the fresh state towards the fibers and then yield to a higher porosity during the dry state $[15,39]$.

However, there is an exception in the case of HC-1 concrete, which has less porosity. This result is due to the poor dispersion of hemp fibers in the concrete for an addition higher than $0.5 \%$. Above this value, hemp balls are formed causing heterogeneous parts in the cement matrix and preventing water from entering some parts of the composite, therefore, it is less porous. In addition, the porosity values of $\mathrm{HC}-0.25$ concretes compared to $\mathrm{AC}-1$ concretes are lower, probably due to the morphological structure of the fibers, which varies from one type to another. 


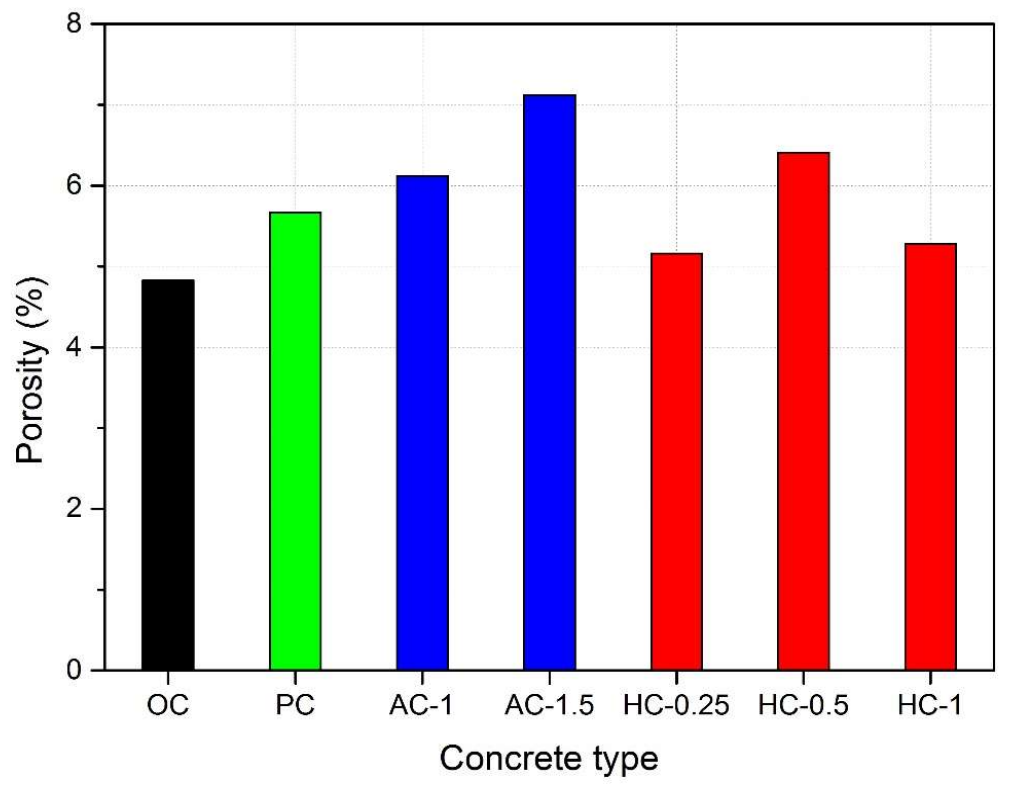

Fig. 4. Porosity of the studied concretes at 28 days

\subsection{Capillarity water absorption of composites}

Figure 5 shows the evolution of the water absorption of all concretes after $24 \mathrm{~h}$ of submersion. From the obtained results, it can be seen that the incorporation of fibers in the concretes increases the water absorption of the composites. It can also be seen that the level of water absorption depends on the amount of fibers in the composites; the higher the amount of fiber, the higher the water absorption.

The results also show that Alfa concrete has more capillary absorption than hempreinforced concrete. The reason for this can be explained by the larger channel created by the Alfa fibers in the composite (the size of the capillaries) and their lower flexibility compared to hemp fibers. 


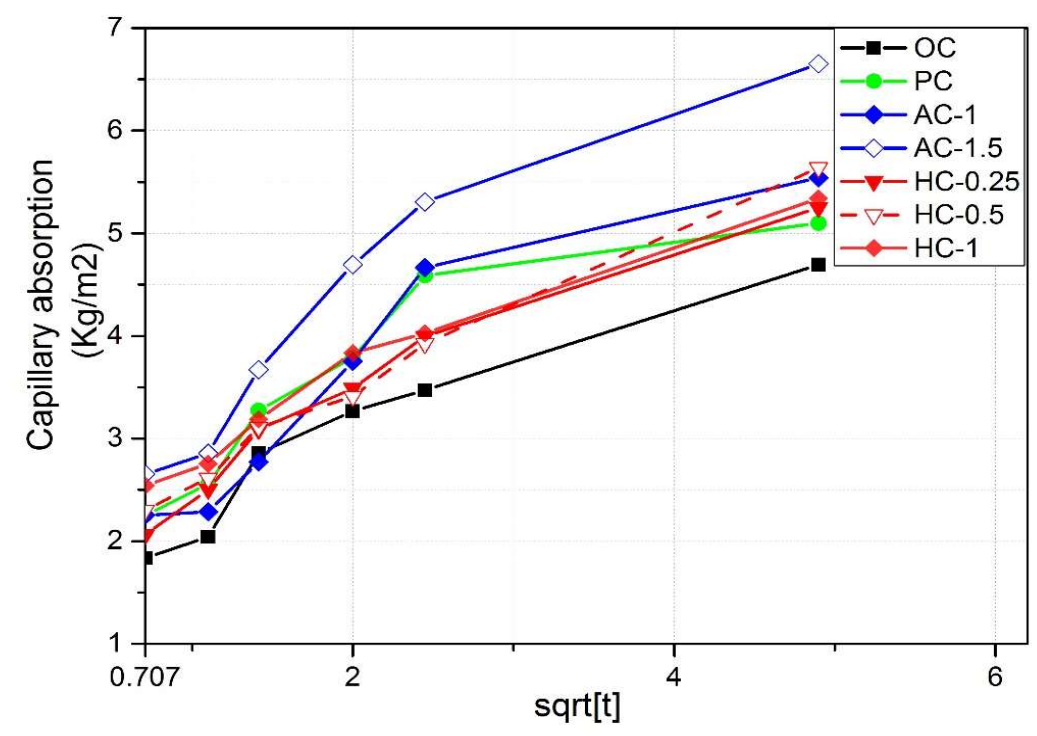

Fig. 5. Evolution of the water absorption of the studied concretes

\subsection{Mass loss monitoring}

The mass loss monitoring is presented in Figure 6. It can be seen for all concretes that there is a first step of a significant mass loss which varies between $0-0.90 \%$ from zero to 28 days. After this, there is a second step between 28-120 days, which is characterized by a slower mass loss that varies between 0.65 and $1.17 \%$. This behavior is related to the incorporated fibers that act as drains for water migration between the concrete and its environment.

This loss of mass varies depending on the type and amount of the fibers. If the fiber amount is increased, the loss of mass is significant due to the high porosity created by the incorporated fibers.

A comparison of the results for the concretes with the optimal amount fiber (PC, $\mathrm{HC}-0.25$, and $\mathrm{AC}-1$ ) shows that the loss of mass of polypropylene (PC) concrete is higher than that of Alfa (AC) and hemp (HC) concrete. This is explained by the fact that the plant fibers can retain water due to their porosity, which polypropylene does not absorb. In addition, HC- 0.25 has a lower mass loss compared to AC-1 due to the concrete porosity and the initial amount of water in the mixtures. 


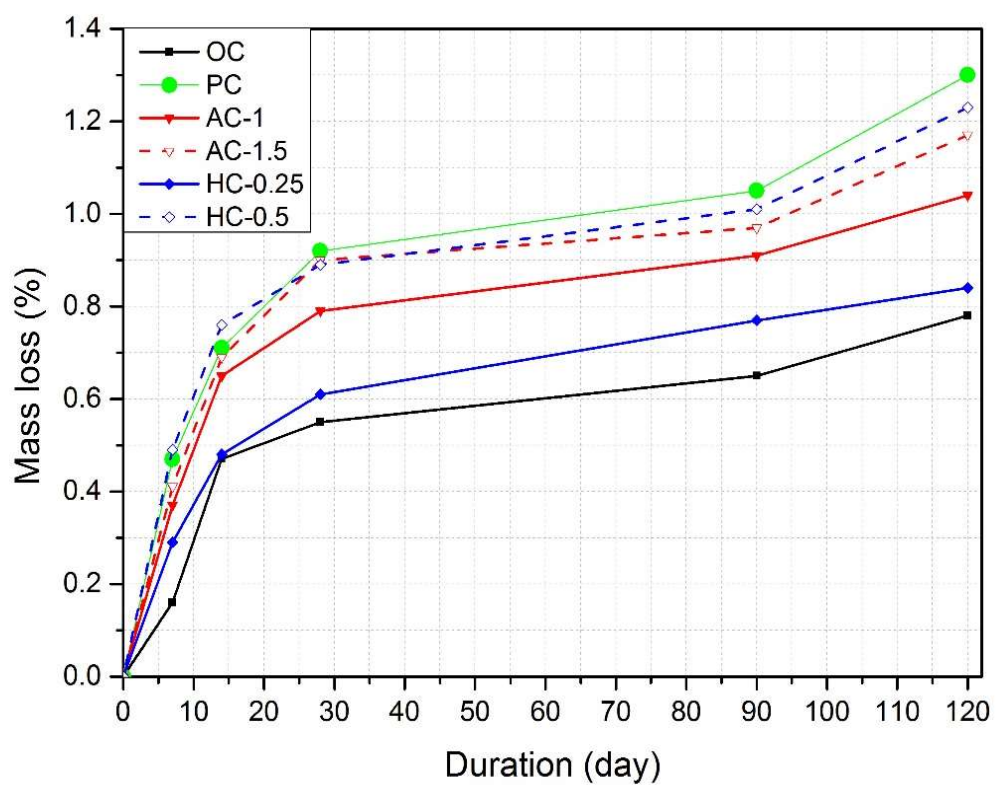

Fig. 6. Evolution of the total mass of all concretes

\subsection{Mechanical properties}

\subsubsection{Compressive strength}

The variations in compressive strength of composites at 7, 28, 90, and 120 days of curing are illustrated in Figure 7. The results indicate that there is a decrease in strength with increasing fiber content for all composites. Despite this decrease, the measured values remain in the range of common structural concrete, more specifically, for PC, AC-1, and HC-0.25 concretes. This drop in strength of fiber reinforced concrete is due to the creation of large numbers of pores or voids as a result of poor distribution of the porous fibers in the cement matrix [40, 41]. In addition, the higher the Alfa and hemp fiber content, the lower the compressive strength.

The results also show that the dosage of $1 \%$ by volume is not valid for all plant fibers due to the different characteristics of each plant fiber. In concrete containing $1 \%$ of hemp fibers, the compressive strength has been reduced by $34 \%$ compared to ordinary concrete, however, $1 \%$ of Alfa fibers will reduce this compressive strength by $10 \%$ only. According to these results, it can be seen that the optimal dosage for hemp fibers is $0.25 \%$ by volume, while a dosage of $1 \%$ by volume is the optimal amount for Alfa fibers.

In addition, the comparison between the two concretes reinforced with plant fibers shows that HC-25 has a better compressive strength than AC-1. This can be 
explained by the diameter of the Alfa fibers, which is larger than the hemp fibers, resulting in the creation of large voids in the composite, thereby reducing its strength.

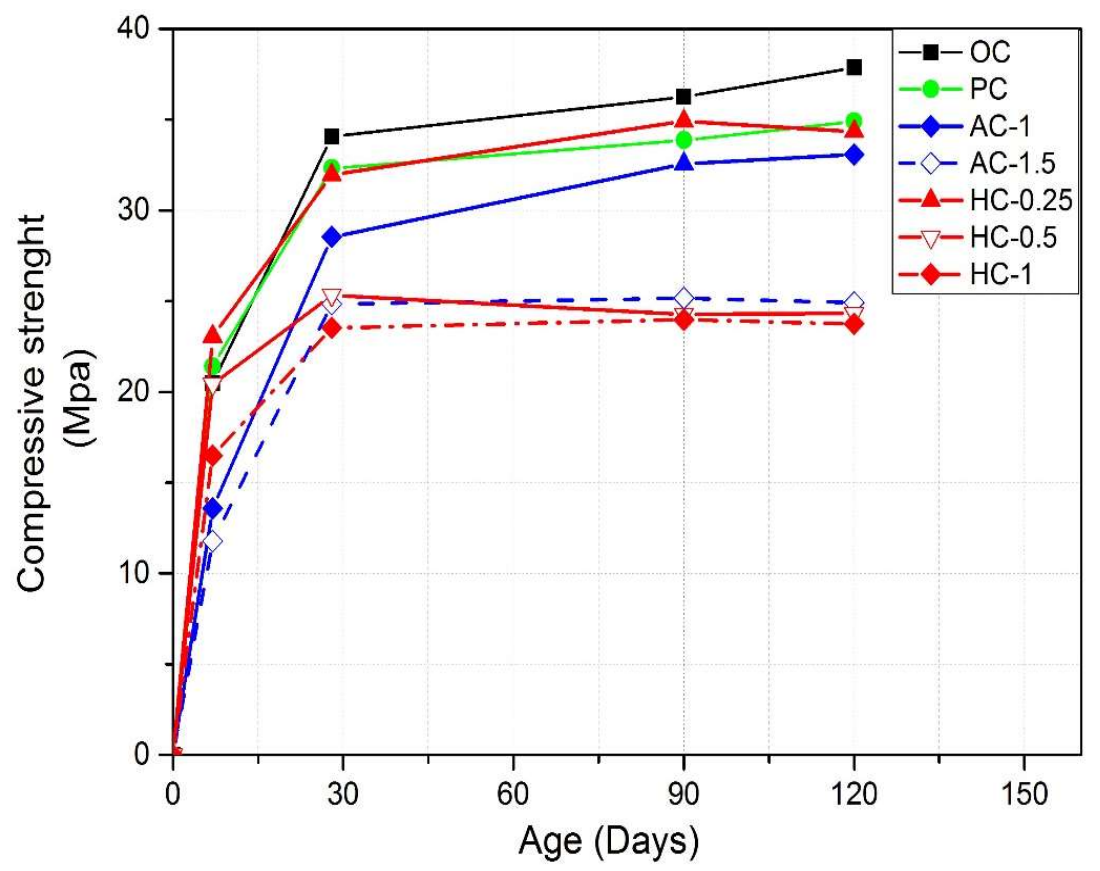

Fig. 7. Compressive strength of the studied concretes

\subsubsection{Flexural tensile strength}

Figure 8 shows the variations in the flexural tensile strength of all concrete mixes after 7, 28, 90, and 120 days of curing. The flexural tensile strength HC-1 (4.72 $\mathrm{MPa})$ and $\mathrm{AC}-1.5(5.67 \mathrm{MPa})$ is lower than the reference concrete OC (5.83 MPa), whilst it is higher for AC-1, PC, HC-0.25, and $\mathrm{HC}-0.5(7.16,7.38$, and $6.95 \mathrm{MPa}$, respectively). The explanation for this behavior seems to be related to the role played by the fiber in the composite, which limits the propagation and progression of the cracks by a sewing effect; which increases the tensile strength of the composites. These results are in agreement with previous research for other types of vegetable fibers $[42,43]$.

On the other hand, the decrease in bending tensile strength for HC-1 compared to HC- 0.25 is due to the amount of fibers incorporated in the composite. This result confirms the amount of $0.25 \%$ of hemp fiber as optimal. In addition, the decrease in bending flexural tensile strength for HC-1 and AC-1.5 is due to the amount of fibers incorporated in the composite. The agglomeration phenomenon is favored 
in this case, which will generate zones with a cluster of non-adhesive fibers in the cementitious matrix. This behavior is probably due to the effect of the superposition of two potential phenomena; the effect of the fibers not uniformly dispersed in the matrix and the weakening of the cementitious matrix caused by the creation of voids and the volume reduction in cement.

It should be noted that the use of $0.25 \%$ of Hemp fibers (HC-0.25) or $1 \%$ of Alfa fibers (AC-1) offers a tensile strength practically identical to that of PC. These findings confirm once again that HC- 0.25 and AC- 1 concretes are the optimal natural reinforced concrete. The comparison between AC-1 and HC-0.25 shows that $\mathrm{AC}-1$ has better flexural tensile strength, and this behavior is related to the tensile strength of Alfa fibers, which is greater than hemp fibers and, therefore, has superior behavior in the composite.

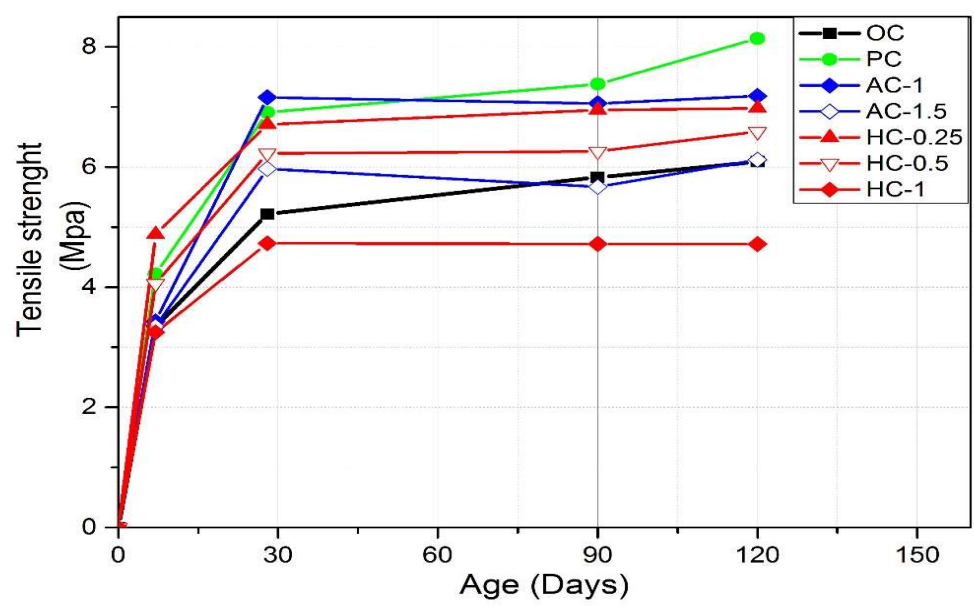

Fig. 8. Flexural tensile strength of the studied concretes

\subsubsection{Dynamic modulus of elasticity}

Figure 9 depicts the results of the dynamic modulus of elasticity for all the studied concretes. All fiber-reinforced concrete results were lower than those for OC. When fibers were added to an ordinary concrete, it reduced the stiffness and increasing the ductile behavior [10].

Furthermore, the greater the amount of hemp and Alfa fibers, the lower the Young's modulus, as a result of the concrete becoming more porous. In addition, the Young's modulus of HC- 0.25 is the optimum for the hemp fibers reinforced concrete. In the case of Alfa fibers, the optimal amount that gives the higher results is $1 \%$ in volume.

These results confirm that the variation of young's modulus for plant fiberreinforced concrete does not depend on the length of the fibers, but rather on their amount and distribution into the matrix [44]. The characteristics of the fiber also 
have an effect; the results show that HC- 0.25 has a better dynamic modulus of elasticity compared to AC-1, and this can be explained by the large diameter of Alfa fiber which causes a higher porosity and, therefore, less stiffness.

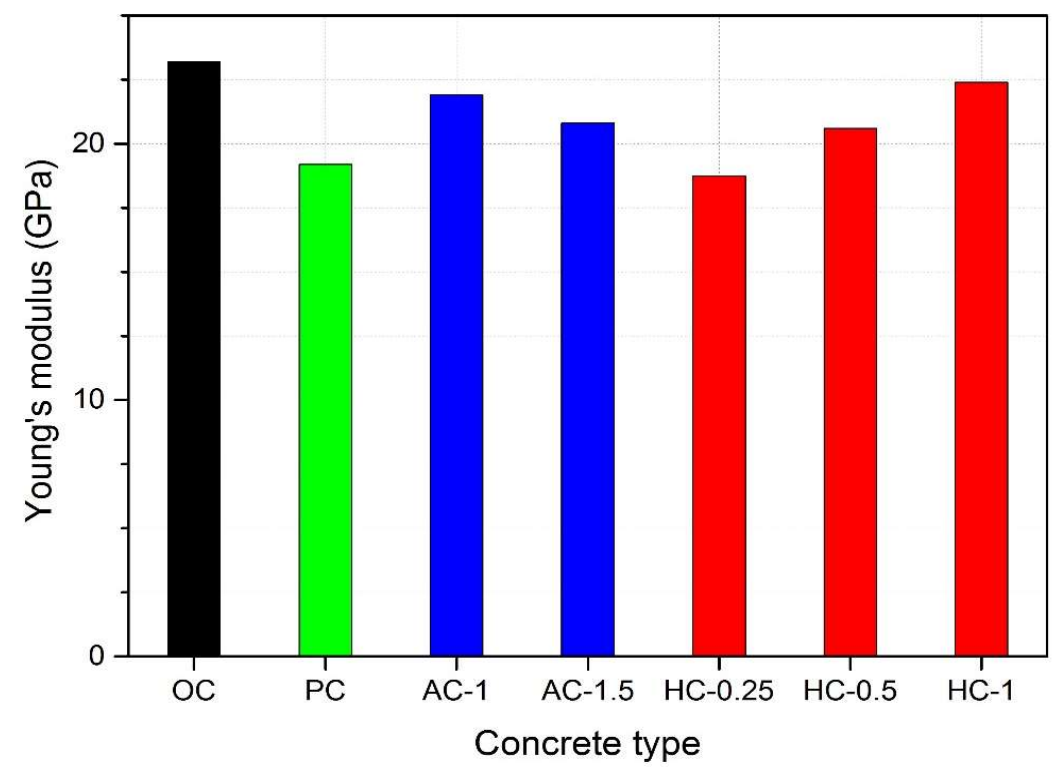

Fig. 9. Young's modulus of the studied concretes at 28 days

\subsection{Sulfatic attacks results}

\subsubsection{Complete immersion}

A. Mass monitoring:

Figure 10 shows the evolution of mass monitoring as a function of the complete immersion time of the different concrete samples.

Analysis of the results shows that all the different concretes kept in sodium sulfate solution had a mass gain of 0 to 50 days of immersion. OC and PC have similar behavior with regard to mass monitoring, followed by the vegetable fiber reinforced concretes (HC-0.25, HC-0.5, AC-1, and AC-1.5). This gain is attributed to the formation of gypsum and secondary ettringite as a result of the reaction between the hydrates and, particularly, portlandite and sulfates in the solution [38]. After 50 days until the end of testing, all the concretes have the same behavior, with a total mass gain of about $3 \%$ after the entire immersion period.

AC-1.5 and HC-0.5 have different behavior to the other samples and are damaged at the end of immersion. These concretes are characterized by a very porous 
structure due to a high fiber content, which allows the formation and deposition of the expansive products of the sulfate reaction.

Note that AC-1 and $\mathrm{HC}-25$ have a slightly higher mass gain in the composites compared to PC-containing fibers, which can be explained by the fact that the mass gain is, therefore, related to the porosity of the matrix as well as the porosity of the fibers.

In addition, AC-1 is slightly higher than HC-25, probably due to the higher fiber content in the composite and the difference in fiber diameter.

The results show that the behavior of concrete in the sulfate environment depends on the physical characteristics of the composites studied.

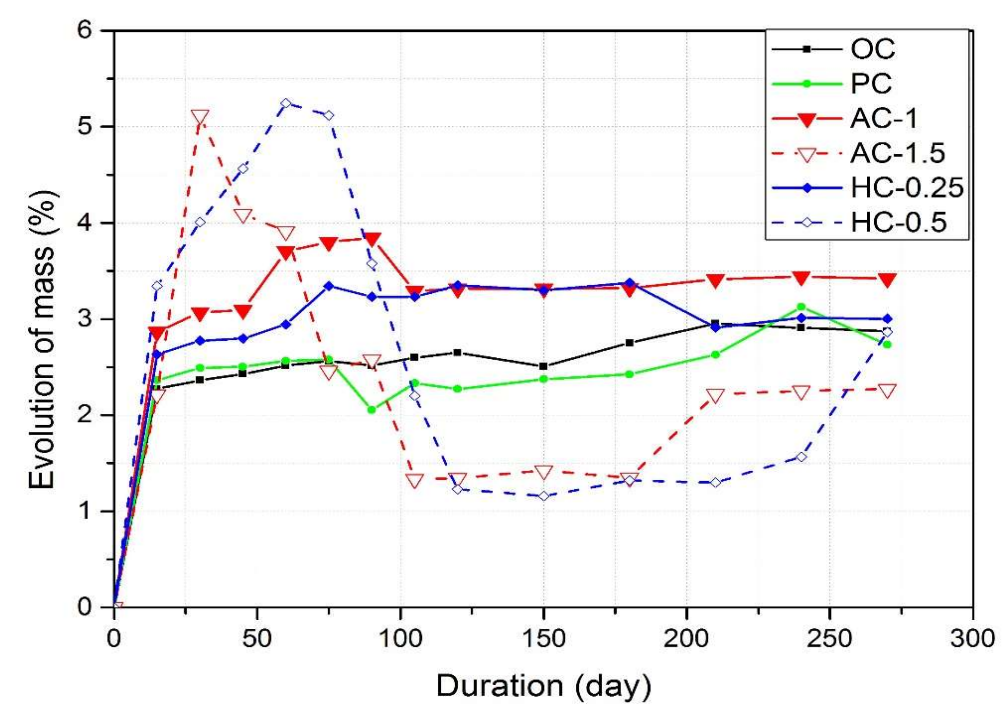

Fig. 10. Mass monitoring of made-up concretes (case of total immersion in $\mathrm{Na}_{2} \mathrm{SO}_{4}$ )

B. Variation of the compressive strength:

Figure 11 shows the compressive strength as a function of full immersion time for the four types of concrete. It can be seen that from zero to 45 days, the compressive strengths of PC and OC samples increase by $5.88 \%$ and $14.54 \%$, respectively, while they decrease slightly for the two vegetable fiber reinforced concretes (HC0.25 and $\mathrm{AC}-1$ ), by $5.79 \%$ and $5.63 \%$, respectively. Then, the trend reverses slightly between 45 and 90 days for these two concretes, being $11.05 \%$ for HC0.25 and $7.30 \%$ for $\mathrm{AC}-1$. The same observations were made for the other vegetable fiber concretes (AC-1.5 and $\mathrm{HC}-0.5)$. OC and $\mathrm{PC}$ concretes remain almost stable, without significant change.

Between 90 and 180 days, the compressive strengths of the different concretes exposed to total immersion increase slowly until the end of this protocol. At the 
end of this protocol, the best compressive strength, after 9 months of immersion in sodium sulfate, is obtained for PC, HC- 0.25 , and AC- 1 concrete.

The difference between $\mathrm{HC}-0.25$ and AC- 1 was not significant, probably due to the high porosity in the Alfa concrete, which absorbs more chemical solution (sodium sulfate), rapidly degrading the fiber, and consequently the compressive strength.

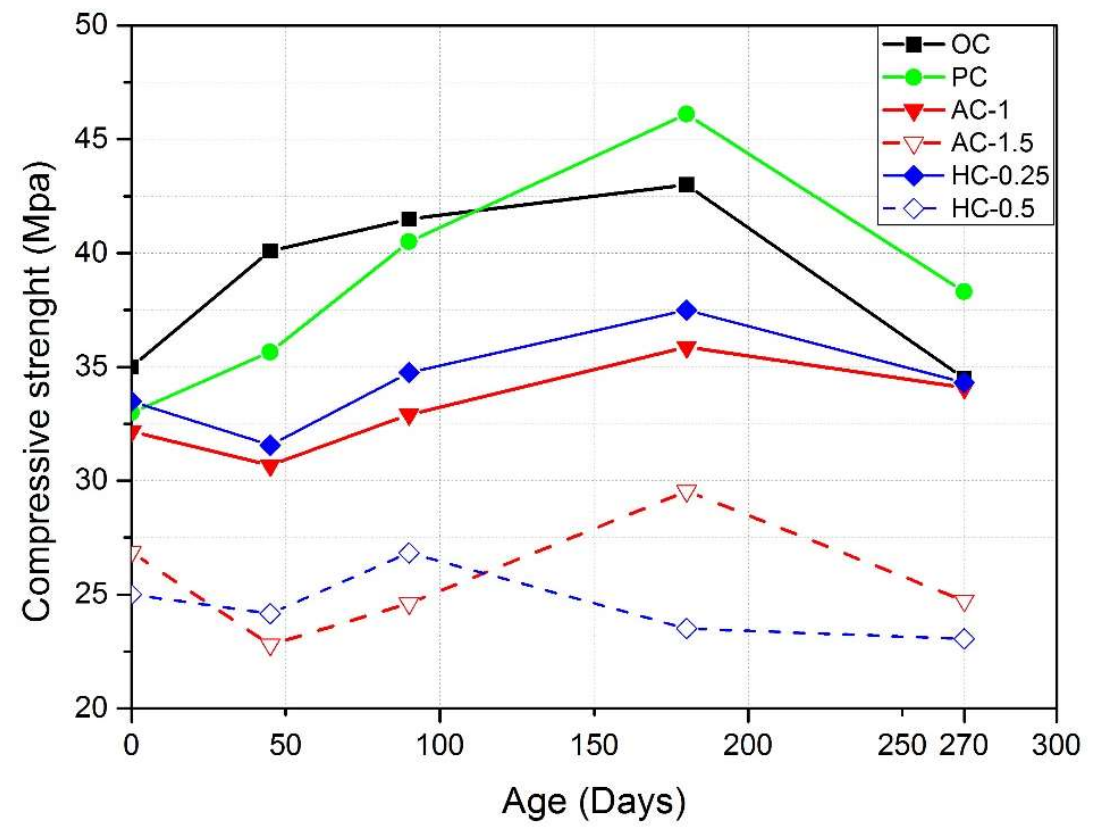

Fig. 11. Evolution of compressive strength (total immersion in $\mathrm{Na}_{2} \mathrm{SO}_{4}$ )

C. Macroscopic monitoring:

The macroscopic observation of samples shows that after 18 months of complete immersion, the samples demonstrate no evidence of swelling or cracking visible to the naked eye (Figure 12), suggesting the absence of a significant external sulfatic attack.

These results suggest that there was a lack of external sulfatic attack of sufficient magnitude to cause damage visible to the naked eye. These results are consistent with previous work $[21,45]$. 


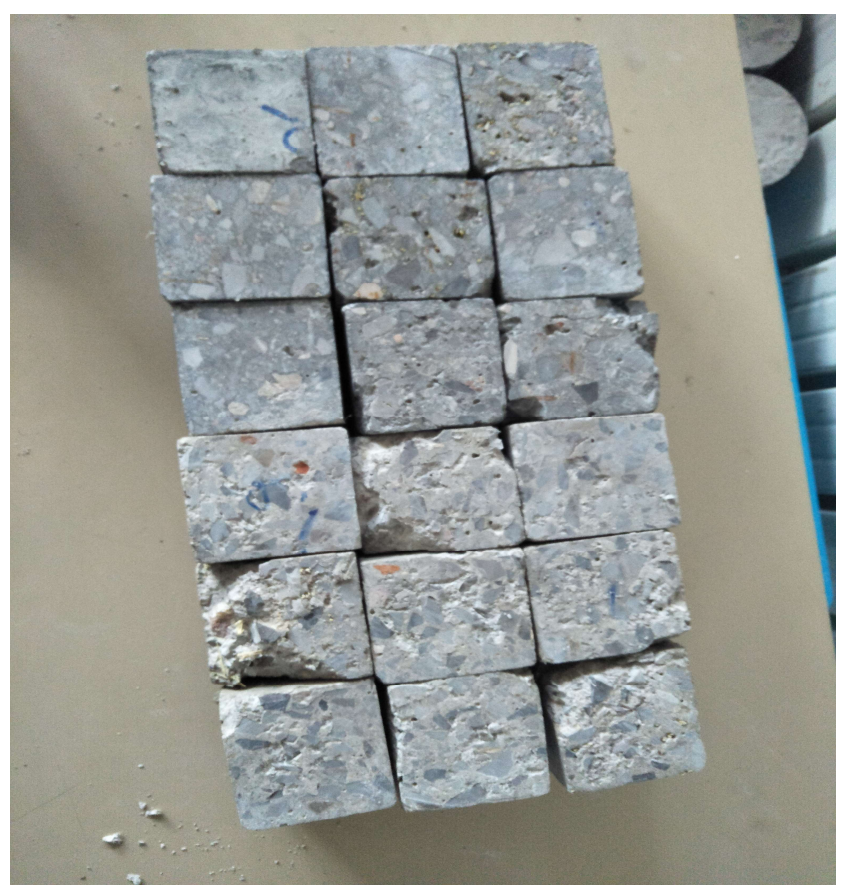

Fig. 12. Photos of samples just after they are released from the Sulfatic attack (complete immersion)

\subsubsection{Results of the immersion drying cycles at $60^{\circ} \mathrm{C}$}

A. Mass monitoring:

The aim of this part of the study is to observe the evolution of the mass of the degraded samples (AC-1, AC-1.5, HC-0.25, and HC-0.5) and that of the PC and OC control concretes, and then compare concrete reinforced with vegetable fibers. Figure 13 shows the evolution of mass monitoring for all concretes in 60 cycles. Between 0 cycles and 60 cycles, all concretes have 1 to $3 \%$ mass gain, which is interpreted as the result of salt crystallization and trapping of solution within the porosity of the concrete. HC- 0.25 and PC concrete have a very similar behavior during mass monitoring.

HC-0.25 and AC-1 have an almost similar behavior from the beginning of the protocol to the end. They record the largest mass increase, which is $3.5 \%$. 


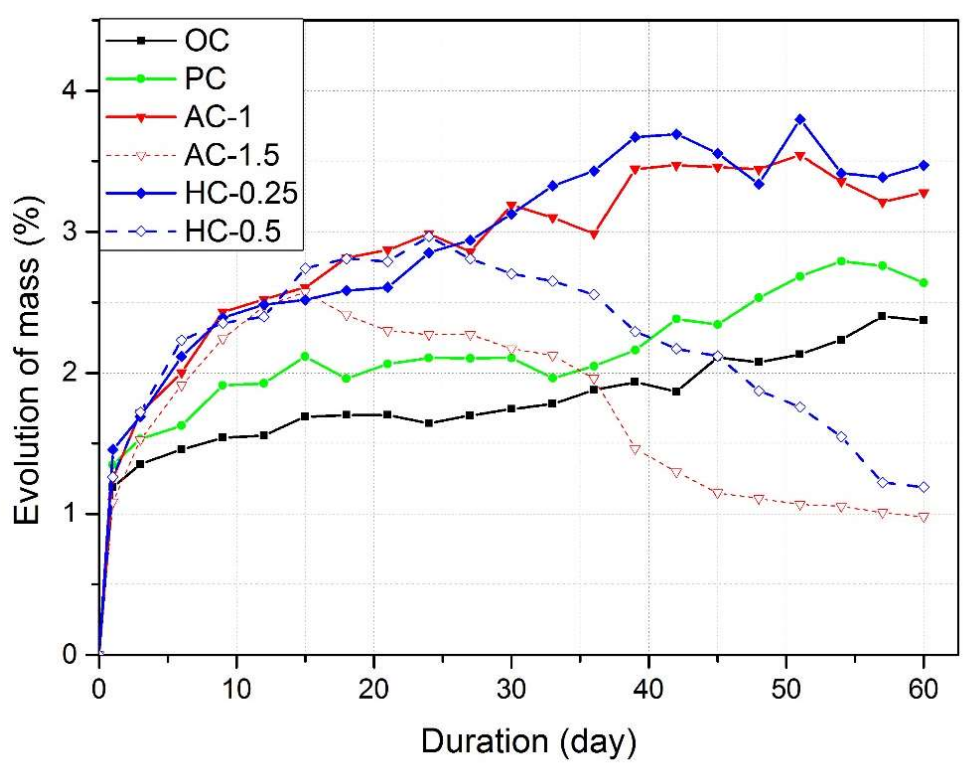

Fig. 13. Mass monitoring of made-up concretes (immersion/drying cycles at $60^{\circ} \mathrm{C}$ )

B. Variation in compressive strength:

The evolution of compressive strengths of all concretes studied at 0,5 , and 15, 30, and 60 cycles of immersion / drying cycles are shown in Figure 14.

In general, compressive strength increases from zero to 15 cycles, which can be explained by the crystallization of salts in the porosity of the concrete [46], which then reinforces the structure. In addition, all concretes evolved through three similar steps, a first step from 0 to 5 cycles where the resistance increases, followed by a slight decrease in resistance from 5 to 15 cycles, and a further decrease between 15 and 60 cycles.

The increase in strength in the first step is due to the continuous hydration of anhydrous cement products and the reaction of sulfate with $\mathrm{Ca}(\mathrm{OH})_{2}$ to form gypsum and ettringite, which complete the micropores, leading to a denser structure which has a positive influence on mechanical strength. Then, a decrease in the last step from 15 to 60 cycles. At the end of this protocol, polypropylene concretes and HC- 0.25 concretes are hardier, this behavior being attributable to the reaction between portlandite $(\mathrm{CH})$ resulting from the hydration of cement with sulfates to form gypsum and ettringite causing microcracks that result in reduced strength [47]. 


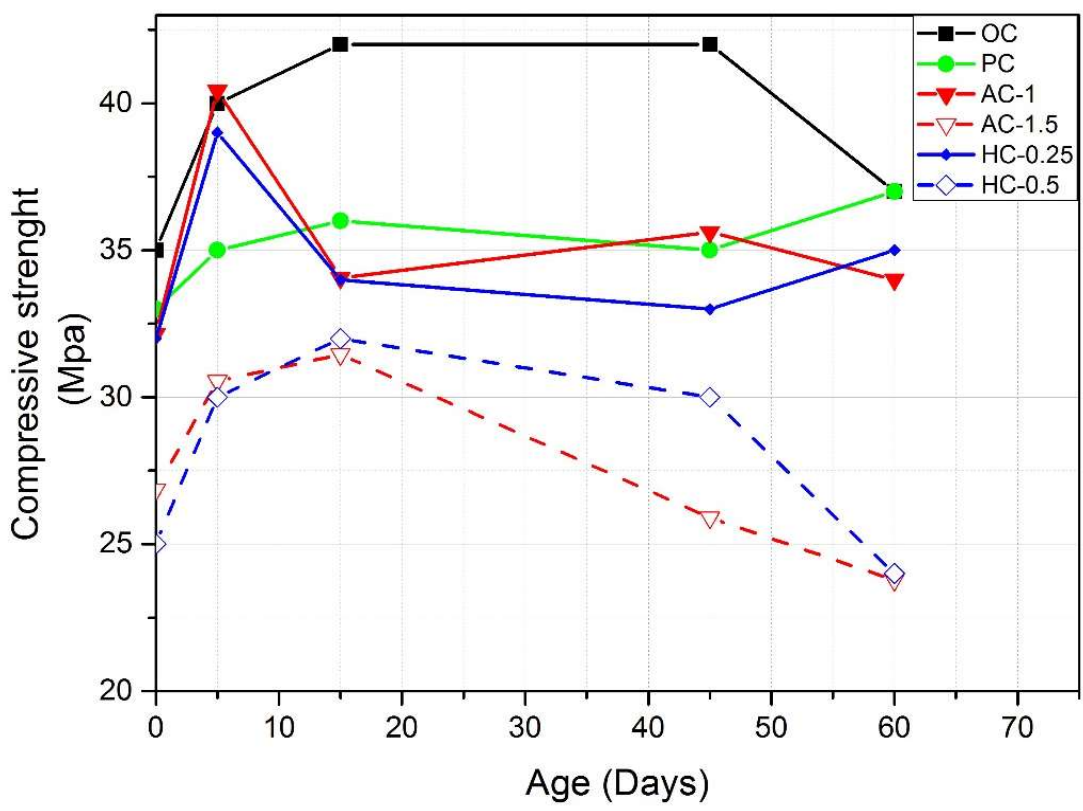

Fig. 14. Evolution of compressive strength (immersion drying /cycles at $60^{\circ} \mathrm{C}$ )

C. Macroscopic monitoring:

During the 60 days of this experimental protocol, photographs were taken regularly before and after immersion, thus providing visual information on the macroscopic evolution of the samples as well as the appearance of possible damage (Figure 15).

Plant fiber reinforced concrete shows visible signs of the beginning of ruin from 45 cycles. The fibers seem to play a role in absorbing the solution, which does not allow crystallization on the surface. This observation was due mainly to the rapid absorption of the solution by the natural fibers in comparison with the synthetic fibers, which resulted in a mass increase and at the same time a degradability of natural fibers and a decrease in the mechanical performance of the made-up concretes. These signs are significant in AC-1.5 and HC-0.5 due to higher amounts of fibers. 


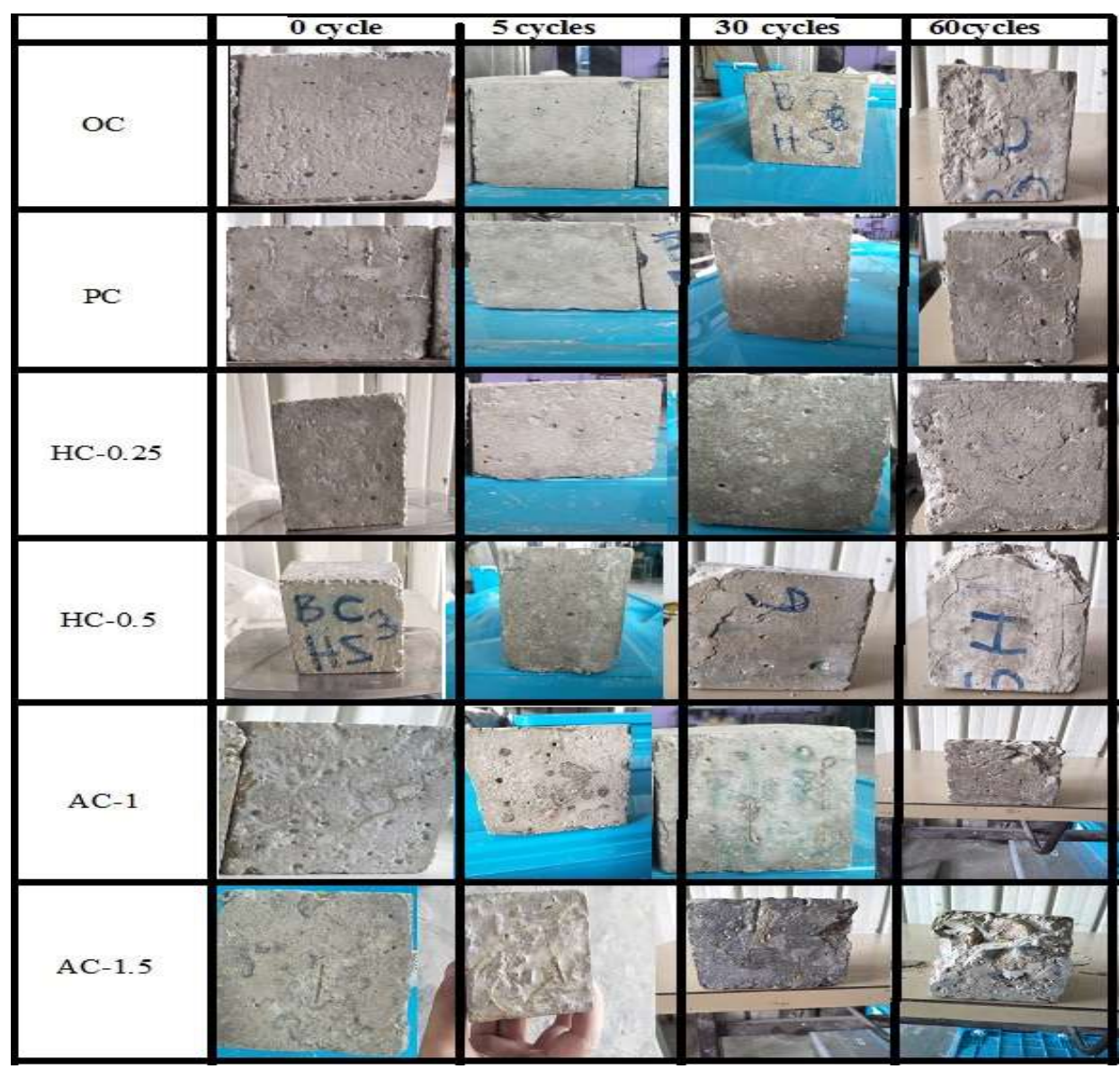

Fig. 15. Photos of samples just after they are released from the Sulfatic attacks (immersion drying cycles at $60^{\circ} \mathrm{C}$ )

\section{Microscopic study (SEM):}

In the case of AC-1 concretes, the picture of their microstructure using a scanning electron microscope (SEM) can clarify the behavior of plant fiber reinforced concrete against external sulfate attack. Figures $16 \mathrm{a}$ and $16 \mathrm{~b}$ clearly show the absence of primary ettringite in the vacuoles of the cement paste at 0 cycles for AC-1. At 15 cycles, the result shows the normal presence of ettringite balls and portlandite (Figures 16c, 16d). Therefore, it can be established that the concrete does not react pathologically to sodium sulfates after 15 cycles of the $60^{\circ} \mathrm{C}$ immersion/drying protocol. 


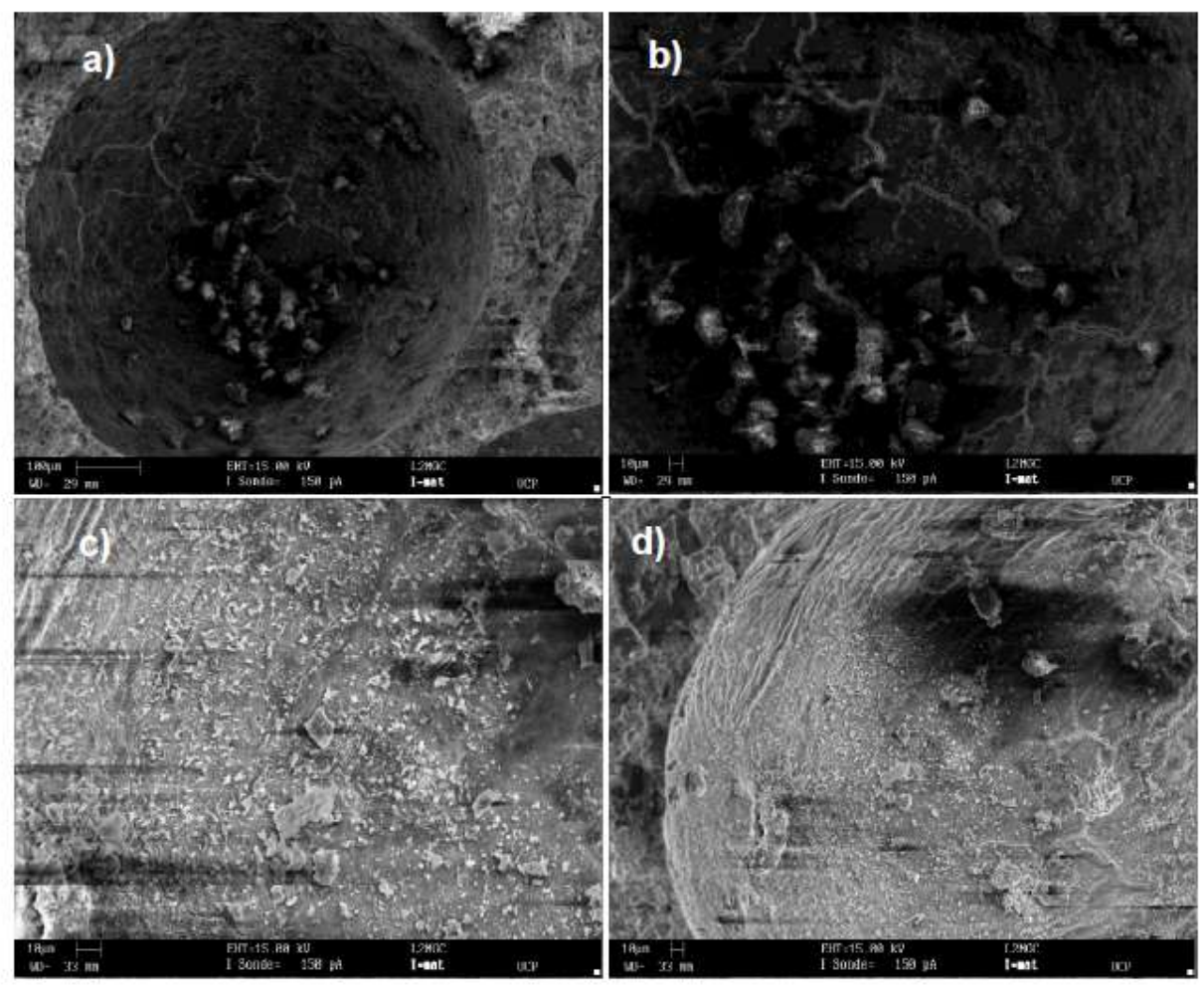

Fig. 16. Microscopic study of AC-1 concrete in the case of immersion drying cycles at $60^{\circ} \mathrm{C}$ : (a) Vacuole of AC-1 concrete $(0$ cycle $)$; (b) Zoom on AC-1 concrete surface $(0$ cycle); (c) Vacuole of AC-1 concrete (15 cycle); (d) Zoom on AC-1 vacuole (15cycle)

\section{CONCLUSION}

Based on the experimental results obtained in this study, the following conclusions can be drawn:

1. Workability, which is a major characteristic of fresh concrete, is affected by both the amount of fiber and its specific features such as porosity and diameter.

2. The incorporation of natural fibers, whether Alfa or hemp, contributes to a decrease in compressive strength and dynamic modulus. Above $1 \%$ in the case of Alfa and $0.25 \%$ in the case of hemp fibers, the compressive strength and dynamic modulus decrease considerably because of the heterogeneous dispersion of the fibers that may form clusters. The increase in voids proportional to the amount of fibers also weakens the concrete affecting its compactness. 
3. The flexural tensile strength of concrete increases with the incorporation of plant fibers. This feature could prevent the rapid spread of cracks in the concrete and sudden bursting in the case of a low-magnitude earthquake.

4. Plant fibers affect the physical properties of cement composites; they contribute to increased porosity and capillary absorption.

5. Alfa and hemp help to increase the loss of mass of the concrete. Thus, significant water transfers are related to the porosity, which depends on the amount of fibers as well as their nature. If the mass loss is important, then it can cause dimensional changes that can generate cracks at short- or long-term intervals in concrete and, therefore, a loss of durability of the structure.

6. The optimum percentage of vegetable fibers varies from one fiber to another, depending on several parameters such as chemical composition, mechanical characteristics, and individual morphology. In this study, $1 \%$ for Alfa and $0.25 \%$ for hemp seem to be the optimal amounts.

7. After more than 9 months of complete immersion, no visible damage (cracking and swelling) and no loss of mass were observed on all the concrete samples despite a decrease in strength of almost $20 \%$. In addition, there was no external sulfatic attack; this result is consistent with previous work [42].

8. There was visible degradation on the samples of plant fiber reinforced concrete, particularly on the high amount of Alfa (AC-1.5) and hemp (HC-0.5) fibers, due to the probable formation of secondary ettringite. AC- 1 and $\mathrm{HC}-0.25$ remain the reference fiber concrete because they present the optimal performance at the end of the immersion/drying protocol at $60^{\circ} \mathrm{C}$, which lasted almost 60 days.

9. The behavior of fiber-reinforced concrete against external sulfatic attack is related to the porosity of the matrix as well as the fibers. A high porosity contributes to facilitating the migration of sodium sulfate ions which can also participate in the increase of the mass of the material and consequently a rapid degradation of the composites.

10. In this study, concrete reinforced with $0.25 \%$ by volume of hemp fibers showed better behavior than concrete reinforced with $1 \%$ of Alfa fibers against external sulfatic attack in both protocols, which is linked to the physical characteristic of each composite (porosity and capillary absorption), but both concretes are acceptable for the production of "green" concrete. These untreated 
EXPERIMENTAL STUDY ON THE DURABILITY CHARACTERISTICS OF SEVERAL VEGETABLE FIBER REINFORCED CONCRETES EXPOSED TO SODIUM SULFATE

natural fibers are commercially available and do not harm the ecosystem compared to polypropylene fibers, which are derived from petroleum.

\section{CONFLICT OF INTEREST}

On behalf of all authors, the corresponding author hereby confirms that there is no conflict of interest.

\section{REFERENCES}

1. Mahdikhani, M, Bamshad, O and Shirvani, MF 2018. Mechanical properties and durability of concrete specimens containing nano silica in sulfuric acid rain condition. Construction and building materials 167, 929-935.

2. Mohammadhosseini, H, Tahir, MM, Sam, ARM, Lim, NHAS and Samadi, M 2018. Enhanced performance for aggressive environments of green concrete composites reinforced with waste carpet fibres and palm oil fuel ash. Journal of cleaner production 185, 252-265.

3. El-Hachem, R, Rozière, E, Grondin, F and Loukili, A 2012. New procedure to investigate external sulphate attack on cementitious materials, Cement and Concrete Composites 34(3), 357-364.

4. Alyami, MH, Alrashidi, RS, Mosavi, H, Almarshoud, MA and Riding, KA 2019. Potential accelerated test methods for physical sulfate attack on concrete. Construction and Building Materials 229, 116920.

5. Mezhoud, S, Clastres, P, Houari, H and Belachia, M 2018. Field Investigations on Injection Method for Sealing Longitudinal Reflective Cracks. Journal of Performance of Constructed Facilities 32(4), 04018041.

6. Mezhoud, S, Clastres, P, Houari, H and Belachia, M 2017. Forensic investigation of causes of premature longitudinal cracking in a newly constructed highway with a composite pavement system. Journal of Performance of Constructed Facilities 31(2), 04016095.

7. Çavdar, A 2014. Investigation of freeze-thaw effects on mechanical properties of fiber reinforced cement mortars. Composites Part B: Engineering 58, 463-472.

8. Çomak, B, Bideci, A and Bideci, ÖS 2018. Effects of hemp fibers on characteristics of cement based mortar. Construction and Building Materials 169, 794-799.

9. Xie, X, Zhou, Z, Jiang, M, Xu, X, Wang, Z and Hui, D 2015. Cellulosic fibers from rice straw and bamboo used as reinforcement of cement-based composites for remarkably improving mechanical properties. Composites Part B: Engineering 78, 153-161. 
10. Ferreira, S. R, Pepe, M, Martinelli, E, de Andrade Silva, F and Toledo Filho, R. D 2018. Influence of natural fibers characteristics on the interface mechanics with cement based matrices. Composites Part B: Engineering 140, 183-196.

11. El Achaby, M, Kassab, Z, Barakat, A and Aboulkas, A 2018. Alfa fibers as viable sustainable source for cellulose nanocrystals extraction: Application for improving the tensile properties of biopolymer nanocomposite films. Industrial Crops and Products 112, 499-510.

12. Page, J, Khadraoui, F, Boutouil, M and Gomina, M 2017. Multi-physical properties of a structural concrete incorporating short flax fibers. Construction and Building Materials 140, 344-353.

13. Sellami, A, Merzoud, M and Amziane, S 2013. Improvement of mechanical properties of green concrete by treatment of the vegetals fibers. Construction and Building Materials 47, 1117-1124.

14. Kriker, A, Debicki, G, Bali, A, Khenfer, M. M and Chabannet, M 2005. Mechanical properties of date palm fibres and concrete reinforced with date palm fibres in hot-dry climate. Cement and Concrete Composites 27(5), 554564.

15. Achour, A, Ghomari, F and Belayachi, N 2017. Properties of cementitious mortars reinforced with natural fibers. Journal of adhesion science and Technology 31(17), 1938-1962.

16. Sudin, R and Swamy, N 2006. Bamboo and wood fibre cement composites for sustainable infrastructure regeneration. Journal of materials science 41(21), 6917-6924.

17. Marrakchi, Z, Khiari, R, Oueslati, H, Mauret, E and Mhenni, F 2011. Pulping and papermaking properties of Tunisian Alfa stems (Stipa tenacissima) effects of refining process. Industrial Crops and Products 34(3), 1572-1582.

18. Imane, M, Khelifa, MR and Mezhoud, S 2020. Impact of Elevated Temperature on the Properties of Concretes Reinforced with Alfa Fiber. Civil and Environmental Engineering Reports 30(3), 161-185.

19. Shahzad, A 2012. Hemp fiber and its composites-a review. Journal of Composite Materials 46(8), 973-986.

20. Florentin, Y, Pearlmutter, D, Givoni, B and Gal, E 2017. A life-cycle energy and carbon analysis of hemp-lime bio-composite building materials. Energy and Buildings 156, 293-305.

21. Khelifa, MR 2009. Effet de l'attaque sulfatique externe sur la durabilité des bétons autoplaçants, Thèse de doctorat en Génie Civil. Ecole Polytechnique de l'Université d'Orléans.

22. Molez, L, Bian, H and Prince-Agbodjan, W 2012. Résistance au gel/dégel des BFUHP: compétition entre endommagement et cicatrisation. Chambéry, Savoie: XXXe Rencontres de l'AUGC-IBPSA. 
EXPERIMENTAL STUDY ON THE DURABILITY CHARACTERISTICS OF SEVERAL VEGETABLE FIBER REINFORCED CONCRETES EXPOSED TO SODIUM SULFATE

23. Khelifa, MR, Leklou, N, Bellal, T, Hebert, RL and Ledesert, BA 2018. Is alfa a vegetal fiber suitable for making green reinforced structure concrete? European Journal of Environmental and Civil Engineering 22(6), 686-706.

24. Dallel, M 2012. Evaluation du potentiel textile des fibers d'Alfa - (Stipa Tenacissima L.) : Caractérisation physico-chimique de la fiber au fil [Evaluation of potential textile fiber Alfa - (Stipa tenacissima): Physicochemical characterization of the fiber over, $\mathrm{PhD}$ Thesis. Haute Alsace University, Mulhouse.

25. Maghchiche, A, Haouam, A and Immirzi, B 2013. Extraction and characterization of Algerian Alfa grass short fibers (Stipa Tenacissima). Chemistry \& Chemical Technology (7,№ 3), 339-344.

26. Sedan, D, Pagnoux, C, Smith, A and Chotard, T 2008. Mechanical properties of hemp fibre reinforced cement: Influence of the fibre/matrix interaction. Journal of the European Ceramic Society 28(1), 183-192.

27. NF EN 197-1 2000. Cement - part 1: Compositions. Specifications and conformity criteria for common cement. Brussels: European Committee for Standardization.

28. NF EN934-2 2012. Adjuvants pour bétons, mortier et coulis - Partie 2: adjuvants pour béton - Définitions, exigences, conformité, marquage et étiquetage.

29. NF EN 12350-2 Avril 2012. Essais pour béton frais - Partie 2: essai d'affaissement Testing fresh concrete - Part 2: Slump test], in french.

30. NF P15-471 Essais des Bétons - Essais Destructifs, Norme Française homologuée.

31. NF P 18-414 1993. Essais des Bétons - Essais Non Destructifs. Mesure de la Fréquence de Résonance Fondamentale [Testing of concrete - non-destructive testing - Measurement of the fundamental resonance frequency]. French: AFNOR.

32. AFPC-AFREM 1997. Recommended methods for measuring of durability parameters. Proceedings of the technical AFCP/AFREM days on concrete durability, Toulouse (pp. 125-134). 11 and 12 December.

33. Ghrici, M, Kenai, S and Meziane, E 2006. Mechanical and durability properties of cement mortar with Algerian natural pozzolana. Journal of Materials Science 41(21), 6965-6972.

34. Kevin, B 2006. Etude des propriétés hydriques et des mécanismes d'altération de pierres calcaires à forte porosité, Thèse de doctorat en Sciences des Matériaux. Université d'Orléans.

35. Brunetaud, X 2005. Etude de l'influence des différents paramètres et leurs interactions sur la cinétique et l'amplitude de la réaction sulfatique interne au béton, Thèse de doctorat en Physico-chimie des Matériaux. Ecole Centrale de Paris. 
36. Brunetaud, X, Linder, R, Divet, L, Duragrin, D and Damidot, D 2007. Effect of curing conditions and concrete mix design on the expansion generated by delayed ettringite formation. Materials and Structures 40(6), 567-578.

37. Lane, DS and Ozyildirim, HC 1999. Evaluation of the potential for internal sulfate attack through adaptation of ASTM C 342 and the Duggan test. Cement, Concrete and aggregates 21(1), 43-58.

38. Ziane, S, Khelifa, MR and Mezhoud, S 2020. A study of the durability of concrete reinforced with hemp fibers exposed to external Sulfatic attack. Civil and Environmental Engineering Reports 30(2), 158-184.

39. Magniont, C 2010. Contribution to the formulation and characterization of an eco-building material based on agricultural resources, $\mathrm{PhD}$ Thesis in Civil Engineering. Toulouse. Toulouse University.

40. Khan, M, Rehman, A and Ali, M 2020. Efficiency of silica-fume content in plain and natural fiber reinforced concrete for concrete road. Construction and Building Materials 244, 118382.

41. Ramaswamy, HS, Ahuja, BM and Krishnamoorthy, S 1983. Behaviour of concrete reinforced with jute, coir and bamboo fibres. International Journal of Cement Composites and Lightweight Concrete 5(1), 3-13.

42. Wei, J and Meyer, C 2015. Degradation mechanisms of natural fiber in the matrix of cement composites. Cement and Concrete Research 73, 1-16.

43. de Andrade Silva, F, Toledo Filho, RD, de Almeida Melo Filho, J and Fairbairn, EDMR 2010. Physical and mechanical properties of durable sisal fiber-cement composites. Construction and building materials 24(5), 777785.

44. Morlier, P and Khenfer, M 1991. Effect of the length of fibers on the mechanical-properties of cements reinforced with cellulosic fibers. Materials and structures 24(141), 185-190.

45. Ziane, S, Khelifa, MR, Mezhoud, S and Medaoud, S 2020. Durability of concrete reinforced with alfa fibres exposed to external sulphate attack and thermal stresses. Asian Journal of Civil Engineering 21(3), 555-567.

46. John, MJ and Anandjiwala, RD 2008. Recent developments in chemical modification and characterization of natural fiber-reinforced composites. Polymer composites 29(2), 187-207.

47. Al-Dulaijan, SU, Maslehuddin, M, Al-Zahrani, MM, Sharif, AM, Shameem, $M$ and Ibrahim, M 2003. Sulfate resistance of plain and blended cements exposed to varying concentrations of sodium sulfate. Cement and Concrete Composites 25(4-5), 429-437.

Editor received the manuscript: 10.10.2020 